\title{
Evaluation of the ventriculocholecystic shunt-an overview of present practice in adult and pediatric hydrocephalus
}

\author{
Cezar Octavian Morosanu ${ }^{1}$ (D) $\cdot$ Adelina Priscu $^{2} \cdot$ Ioan Stefan Florian ${ }^{3}$
}

Received: 5 August 2020 / Revised: 30 December 2020 / Accepted: 4 January 2021 / Published online: 22 January 2021

(C) Crown 2021

\begin{abstract}
In the context of hydrocephalus, there are a multitude of therapeutic options that can be explored in order to improve patient outcomes. Although the peritoneum is the current elected clinical solution, various receptacles have been utilized when experiencing contraindications. Along with the ventriculoatrial or ventriculopleural, the ventriculocholecystic shunt was also described as an alternative. In order to make a decision on a place for drainage, the surgeon must be knowledgeable on details from modern literature. The main target of this review was to summarize the currently available information on this topic and assess the status of the gallbladder as a viable option for cerebrospinal fluid diversion.
\end{abstract}

Keywords Hydrocephalus $\cdot$ Gallbladder $\cdot$ Ventriculocholecystic $\cdot$ Biliary shunt

\section{Introduction}

The ventriculocholecystic shunt (VCS), also called a ventriculo-gallbladder or ventriculobiliary shunt, was first designed by Smith et al. [63] and represents one of the 36 options of receptacles that have been explored for the purpose of adult and pediatric hydrocephalus treatment [43]. When dealing with this neurosurgical pathology, the first treatment choice of cerebrospinal fluid (CSF) diversion is the ventriculoperitoneal (VP) shunt, but in some instances, the device is rendered unfeasible due to various complications. These clinical contraindications steer the therapeutic decision towards other anatomical sites. If the peritoneum cannot support a shunt, the atrium is considered the next viable option. This propensity of electing the ventriculoatrial (VA) shunt as a second option is not guided necessarily by a standard protocol decision, but by the surgeons' experience in this direction. With the exception of the atrial and pleural shunts, choosing

Cezar Octavian Morosanu

cezaroctavian.morosanu@yahoo.com

Department of Neurosurgery, Southmead Hospital, Bristol, UK

2 Department of Internal Medicine, Indiana University Health Ball Memorial Hospital, Muncie, IN, USA

3 Department of Neurosurgery, Cluj County Hospital, Cluj-Napoca, Romania one shunt over another has never undergone a rigorous statistically significant comparison, but has been generated only through the inability of performing a previously mentioned option. The VCS has only been tested when the peritoneum, atrium, or pleura failed in delivering a suitable therapeutic response. At this point, there are no guidelines that can regard the VCS as an immediate solution after the VP shunt, despite the large amount of pertinent studies that have delineated this technique.

The target of this review is to create a full view of the situations in which the VCS has been used for the past 50 years, along with associated physiology that could make it a proper biological candidate for CSF shunting, as well as the complications that could impair its usage in the long term. The questions raised by this review are related to the usefulness of this type of shunt in modern practice aiming to explore the hypothesis that the gallbladder might be a viable cavity that can indirectly relieve intracranial pressure.

\section{Physiology of gallbladder shunting}

There are several aspects that need to be taken into consideration in relation to the underlying physiology governing a proper functioning of a VCS. This involves the mechanisms of storing and secreting the excess fluid in the gallbladder, the size of the gallbladder, the intracholecystic pressure, the 
intraventricular pressure, the difference between the two, and the volume of CSF coming through the shunt.

The gallbladder provides the secretion of bile necessary in gastrointestinal processes. Bile originates in the hepatocytes and consists mainly of water (95\%) and only a small proportion is represented by bile salts, cholesterol, amino acids, phospholipids, bilirubin, and steroids [10]. In the case of a cholecystic shunt, the gallbladder is also responsible for eliminating CSF, done through the relaxation of the sphincter of Oddi.

In the case of the peritoneum or the pleura [33], the principle is to allow the absorption of CSF, whereas for the gallbladder, the main process is storing fluids in order to secrete them in another compartment from where they are later eliminated. The urinary bladder uses the same mechanism in the ventriculovesical shunt [5], but the difference is that the gallbladder can also absorb certain elements such as water, electrolytes [58] and other organic substances [45], whereas the urinary bladder is impermeable [44]. Despite this constituting a minor advantage, the patency of a VCS should rely on the eliminating properties of the gallbladder and not so much on its absorptive capacity. The $\mathrm{pH}$ of the gallbladder content should not be the subject of major alteration given that both fluids have a $\mathrm{pH}$ ranging from 7 to 8 , although there are various elements that can influence the biochemistry of the CSF [7] as well as of the bile [39].

The size of gallbladder is also important as it is necessary to know how much fluid this type of cavity can store. The size increases with age and can be dependent on the type of oral intake [65]. In pediatric patients, gallbladder size can vary from $1.4 \mathrm{~cm}^{3}$ in patients less than 1 year old, to $11.1 \mathrm{c.m} \mathrm{m}^{3}$ in patients up to 16 years old [72]. It is difficult to state how much extra CSF fluid can the gallbladder accommodate, but smaller gallbladders could constitute an issue. Despite this aspect, the majority of VCSs in literature have been performed on children (Table 1).

The first experiments with VCS were performed by Smith et al. (1959) on a dog model [63]. Smith's initial feasibility study determined that the intracholecystic pressure of 10-20 $\mathrm{cmH}_{2} \mathrm{O}$ would maintain a satisfactory intracranial pressure and that the lytic action of the bile would prevent any fibrinous adhesions at the distal segment of the shunt. The physiology of the canine biliary tract does not present significant differences from that of a human [53].

In addition to the already added inner gallbladder pressure, intra-abdominal pressure (IAP) might also play an unfavorable role and increase the intracholecystic pressure. In the case of ventriculoperitoneal shunt, IAP has been shown to increase the risk of shunt failure by contributing to an imbalance in the flow of the CSF [42]. Although no proper studies have been performed to objectively measure this aspect, it is reasonable to suspect that the intracholecystic pressure might be subject to the same physiological process as the ventriculoperitoneal shunt.

Intraventricular pressure (IVP) dynamics in VCS has been studied by Frim et al. in relation to food ingestion and their observations revealed that in the post-prandial period the IVP of the 4-year-old patient rose by $13 \mathrm{cmH}_{2} \mathrm{O}$ with a maximum after $75 \mathrm{~min}$. In patients that require relatively elevated intraventricular pressures to prevent over-drainage phenomena, which can present with chronic headaches or a subdural hematoma, this can be a good thing. Despite having only one patient in their telemetric study, and not a cohort of patients, the authors draw attention to an important issue, that feeding can have an impact on the VCS pressure dynamics [18].

Another aspect highlighted by Henderson et al. is that CSF output in an EVD can have the potential to indicate the prognosis of a shunt. In their experience, the patient who had higher volumes of CSF recorded in the pre-shunt EVD resulted in shunt failure, whereas the cases with lower EVD volumes had a significantly better outcome [26]. Furthermore, Woodfield et al. recommend considering a VA shunt when large volumes of CSF require drainage after managing a pediatric case with craniopharyngioma and CSF overproduction. The patient initially had a VP shunt, which proved to be unable to absorb the increased quantity of fluid, causing the child to develop CSF ascites later on. Then, the next therapeutic option was a VCS, which also failed, suggesting, as Woodfield et al. state, that "in cases where peritoneal absorption has failed due to large volumes of CSF, the gallbladder may not be a suitable alternative" [71].

It should be mentioned that the gallbladder was used on very rare occasions as the site of CSF diversion coming from the lumbar spine in the so-called lumbar-gallbladder shunts. Complications such as chemical meningitis from bile reflux are reported in literature, which is a potential complication of cranial diversions, as well [8]. This raises the question of the biochemical effect that bile has on the cerebral tissue. Although bile is a relatively sterile substance [13, 29], leakage into the peritoneum generates an inflammatory reaction in the form of serous peritonitis [1]. Experimental studies have demonstrated that this is a result of the effect of bile salts rather than bilirubin; in addition, bile also stimulates lipopolysaccharide release enhancing the peritoneal inflammatory response [6]. It is highly possible that the meninges could be subject to the same process. In the case presented by Barami et al., the high acidity of the bile was also incriminated for the patient developing aseptic meningitis, encephalopathy, and severe lumbar arachnoiditis [8]. In the case reported by Bernstein, the effect of bile on the brain was evaluated during the autopsy. This determined the histological changes of brain saponification and emulsification secondary to this type of injurywhich appear to be quite different from the normal appearance of kernicterus. Their findings show that bile caused acute cerebral edema with diffuse neuronal anoxic changes in a 
Table 1 Pediatric hydrocephalus

\begin{tabular}{|c|c|c|c|c|c|c|}
\hline Year & Author & $\begin{array}{l}\text { Number of } \\
\text { patients }\end{array}$ & Age & Previous shunt & Follow-up & Complications \\
\hline 1959 & Smith et al. & 10 & Not specified & Not specified & Not specified & $\begin{array}{l}4 \text { - died } \\
6 \text { - no complications }\end{array}$ \\
\hline 1985 & Berstein et al. & 1 & $5 \mathrm{y}$ & VA, VP & $\mathrm{n} / \mathrm{a}$ & $\begin{array}{l}\text { Death due to neurogenic pulmonary } \\
\text { edema with biliary ventriculitis after }< \\
24 \mathrm{~h} \text { of shunt placement }\end{array}$ \\
\hline 1987 & West et al. & 25 & $6 \mathrm{mo}-16 \mathrm{y}$ & $\begin{array}{l}\mathrm{VP}, \mathrm{VA} \\
1-\text { none }\end{array}$ & $4 \mathrm{mo}-9 \mathrm{y}$ & $\begin{array}{l}\text { Proximal/distal shunt } \\
\text { obstruction/infection, biliary tract } \\
\text { infection, subdural hematoma, } \\
\text { gallbladder atony, ventriculo-small } \\
\text { bowel fistula }\end{array}$ \\
\hline 1993 & Stringel et al. & 8 & $8 \mathrm{w}-15 \mathrm{y}$ & VP, VA & $10 \mathrm{mo}-8 \mathrm{y}$ & $\begin{array}{l}5-\text { no complications } \\
3 \text { - complications (distal end malfunction, } \\
\text { shunt infection, gallbladder atony) }\end{array}$ \\
\hline 1997 & Ketoff et al. & $\begin{array}{l}16 \text { (not specified } \\
\text { how } \\
\text { many were } \\
\text { children) }\end{array}$ & $0.9-23$ y & $\begin{array}{l}\text { VP, VA, VPL, VSaph, 1- } \\
\text { none }\end{array}$ & $4 w-7.5 y$ & $\begin{array}{l}\text { 9- no complications } \\
\text { 7- complications (shunt } \\
\text { obstruction/disconnection/infection, } \\
\text { enterotomy, pseudomembranous } \\
\text { colitis, subdural hematoma, slit } \\
\text { ventricles, cellulitis, wound dehiscence, } \\
\text { unilateral hydrocephalus from } \\
\text { undrained ventricle contralateral to } \\
\text { ventriculostomy) }\end{array}$ \\
\hline 1997 & Novelli et al. & 6 & Not specified & VP, VA, VPL & $8 \mathrm{mo}-8 \mathrm{y}$ & No complications \\
\hline 2000 & $\begin{array}{l}\text { Rajaraman } \\
\text { et al. }\end{array}$ & 1 & $5 \mathrm{y}$ & VP & $\mathrm{n} / \mathrm{a}$ & $\begin{array}{l}\text { Distal end obstruction (retained connector } \\
\text { in the gallbladder) }\end{array}$ \\
\hline 2000 & Frim et al. & 1 & $4 y$ & VP & Not specified & Not specified \\
\hline 2005 & $\begin{array}{l}\text { Hamamcioglu } \\
\text { et al. [23] }\end{array}$ & 1 & $10 \mathrm{y}$ & VP, VPL & Not specified & Not specified \\
\hline 2005 & Olavarria et al. & 4 & $8-12$ mo & VP, VA & $3.5-4 y$ & $\begin{array}{l}\text { 1-no complications } \\
\text { 3- complications (bile reflux, wound } \\
\text { infection following laparotomy for } \\
\text { abdominal pain, unspecified distal } \\
\text { shunt malfunction) }\end{array}$ \\
\hline 2006 & Surfield et al. & 1 & $7 \mathrm{y}$ & VP & $11 \mathrm{y}$ & $\begin{array}{l}\text { Cholelithiasis encrusted on shunt tubing at } \\
18 \mathrm{y} \text {, VCS revision, then symptom-free } \\
\text { at } 3 \text { mo follow-up }\end{array}$ \\
\hline 2007 & Pal et al. & 2 & $3 \frac{1}{2} \mathrm{y}, 6 \mathrm{mo}$ & $\mathrm{VP}, 1$ - none & $21 / 2 y, 3 y$ & No complications \\
\hline 2007 & $\begin{array}{l}\text { Weinzierl } \\
\text { et al. }\end{array}$ & 2 & $6 \mathrm{mo}, 9 \mathrm{mo}$ & VP, VA & $2 \mathrm{y}, 3 \mathrm{y}$ & $\begin{array}{l}\text { Death due to distal shunt occlusion, } \\
\text { Post-prandial headaches after ingestion of } \\
\text { fatty foods, but well-functioning VCS }\end{array}$ \\
\hline 2008 & Aldana et al. & 18 & 4 mo-17 y & 17-VP, VJ, 1-none & $1 \mathrm{w}-8.5 \mathrm{y}$ & $\begin{array}{l}\text { 11-no complications } \\
\text { 7-complications (shunt infection, } \\
\text { proximal/distal malfunctions, "sludge" } \\
\text { in the biliary duct and the CBD, gall- } \\
\text { bladder stones, cholecystitis) }\end{array}$ \\
\hline 2009 & Girotti et al. & 2 & $3 \mathrm{y}, 12 \mathrm{y}$ & VP, VA & $2 \mathrm{y}, 9 \mathrm{y}$ & No complications \\
\hline 2010 & Polo et al. & 4 & $4-13$ y & VP, VA & $10 \mathrm{mo}-3 \mathrm{y}$ & $\begin{array}{l}\text { 3- no complications } \\
\text { 1-Acalculous cholecystitis treated } \\
\text { medically, then prolonged fever } \\
\text { initially thought to be ventriculitis, but } \\
\text { later proved Silastic allergy-VCS was } \\
\text { removed }\end{array}$ \\
\hline 2011 & Weiner et al. & 1 & $13 \mathrm{mo}$ & VP & $\mathrm{n} / \mathrm{a}$ & MRSA Ventriculitis \\
\hline 2012 & Lyngdoh et al. & 2 & $8 \mathrm{y}, 11 \mathrm{y}$ & VP, ETV & $3.4 \mathrm{y}$ & $\begin{array}{l}\text { No complications (however hydrops } \\
\text { noticed on follow-up MR cholangio- } \\
\text { gram) }\end{array}$ \\
\hline 2012 & $\begin{array}{l}\text { Sepulveda } \\
\text { et al. } \\
\text { [59] }\end{array}$ & 1 & Not specified & VP & $18 \mathrm{mo}$ & No complications \\
\hline 2013 & $\begin{array}{l}\text { Demetriades } \\
\text { et al. }\end{array}$ & 2 & $9 \mathrm{mo}, 3 \frac{1}{2} \mathrm{y}$ & ETV, VP & $46 \mathrm{mo}, 28 \mathrm{mo}$ & No complications \\
\hline 2013 & Parikh et al. & 1 & Not specified & VP, VA & $\mathrm{n} / \mathrm{a}$ & $\begin{array}{l}2 \text { episodes of ascending cholangitis, renal } \\
\text { failure, and sepsis at } 26 \mathrm{y} \text {, secondary to }\end{array}$ \\
\hline
\end{tabular}


Table 1 (continued)

\begin{tabular}{|c|c|c|c|c|c|c|}
\hline Year & Author & $\begin{array}{l}\text { Number of } \\
\text { patients }\end{array}$ & Age & Previous shunt & Follow-up & Complications \\
\hline & & & & & & $\begin{array}{l}\text { a retained metallic fragment of a VCS } \\
\text { in the common bile duct }\end{array}$ \\
\hline 2013 & Shakir et al. & 1 & $9 \mathrm{mo}$ & Ventriculosubgaleal & Not specified & $\begin{array}{l}\text { Removal of the shunt after an infection } \\
\text { contracted during a proximal revision } \\
\text { procedure }\end{array}$ \\
\hline 2013 & $\begin{array}{l}\text { Woodfield } \\
\text { et al. }\end{array}$ & 1 & $1 \mathrm{y}$ & VP & $2 y$ & $\begin{array}{l}\text { CSF overproduction which exceeded the } \\
\text { gallbladder capacity }\end{array}$ \\
\hline 2014 & Kulwin et al. & 1 & $9 \mathrm{y}$ & VP & Not specified & Bile peritonitis due to shunt fracture \\
\hline 2015 & $\begin{array}{l}\text { Rivero-Garvia } \\
\text { et al. }\end{array}$ & 3 & $\begin{array}{l}7 \mathrm{y}, 16 \mathrm{mo}, 4 \\
\mathrm{y}\end{array}$ & VP, ETV, VA, Vfem & $45 \mathrm{mo}, 14 \mathrm{mo}, 27 \mathrm{mo}$ & $\begin{array}{l}\text { Case } 1 \text {-No complication } \\
\text { Case } 2 \text {-Valve infection that required } \\
\text { conversion to VP shunt. Died } 14 \mathrm{mo} \\
\text { later of atypical pneumonia } \\
\text { Case } 3 \text { - Disconnected biliary catheter } \\
6 \text { mo after placement }\end{array}$ \\
\hline 2019 & $\begin{array}{l}\text { Henderson } \\
\text { et al. }\end{array}$ & 3 & $2 \mathrm{y}, 2 \mathrm{y}, 8 \mathrm{y}$ & VP, VA, ETV & $\begin{array}{l}22 \mathrm{mo}, 12 \mathrm{mo}, 1- \\
\text { none }\end{array}$ & $\begin{array}{l}2 \text { - no complications } \\
1 \text { - shunt dysfunction (VCS failed due to } \\
\text { high volume of CSF, overwhelming the } \\
\text { drainage capacity of the gallbladder) }\end{array}$ \\
\hline 2019 & Pancucci et al. & 1 & $4 \mathrm{mo}$ & None & $14 \mathrm{mo}$ & No complications \\
\hline 2019 & Ignacio et al. & 1 & $20 \mathrm{mo}$ & VP & $3 \mathrm{y}$ & No complications \\
\hline 2020 & Alraee et al. & 1 & $11 \mathrm{y}$ & VP & $1 \mathrm{y}$ & Gallbladder stones \\
\hline
\end{tabular}

pseudolaminar pattern. The cerebellum had degenerative changes in the Purkinje cells and dentate nuclei, the thalamus, and hypothalamus displayed astrocytosis and gliosis and the cerebral arachnoid had macrophages with bile pigment [9].

\section{Technique and perioperative aspects}

The first technique of VCS was proposed by Smith et al. who performed it on a series of 10 patients, recording a mortality rate of $40 \%$. According to them, the patients did not die of causes related to the actual shunt, but to other comorbidities [63]. The VCS technique has also been attributed to Luis Yarzagaray (1958), but despite his 15 cases being mentioned in the works of Anthony Raimondi, he did not have any personally published observations [54]. Since then, advancements in the operative room and antibiotic therapy have improved patient outcomes. In the preoperative assessment, biliary studies (liver function tests and cholangiography) should be considered, as well as abdominal ultrasound, to identify if any pre-existing biliary pathology would contraindicate a VCS. James et al. emphasize the role of preoperative gallbladder imaging, such as abdominal CT or ultrasonography. Their database includes a case that was considered for VCS, but had gallbladder agenesis and a case that had initial sludge formation identified on ultrasound, which eventually led to shunt blockage and removal [32]. As indicated by Henderson et al., careful consideration should also be made in patients with high EVD drainage levels [26].
Due to the hepatobiliary involvement, the help of a general surgeon, or a pediatric surgeon if the patient is a child, would be a useful addition to the neurosurgical operating room staff.

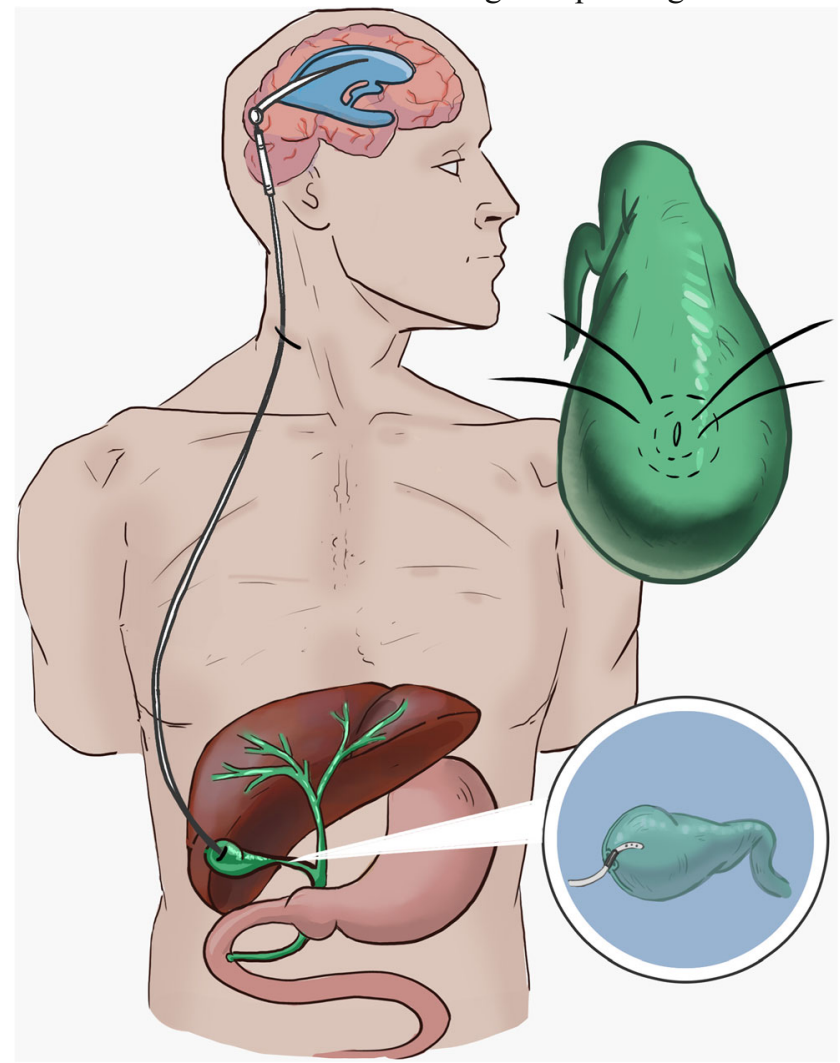

Fig. 1 Ventriculocholecystic shunt. Metal connector inserted in gallbladder and secured with a concentric purse string suture 
After Smith et al., Bernstein et al. reported the case of a 5-yearold who underwent VCS insertion after multiple other shunting attempts. The proximal component of the shunt was always placed in the ventricles using the standard technique. For the distal component, the procedure commenced via a right subcostal incision, which allows access to the fundus of the gallbladder and visualization of the distal segment of the shunt. The distal end of a Raimondi one-piece catheter was used and a cholecystostomy was made in the dome of the gallbladder. A catheter with a low-pressure valve was inserted and afterwards checked for any signs of leakage. Unfortunately, the patient did not have a favorable outcome, but this was the first attempt made by anyone at this procedure after Smith/Yarzagaray [9].

The technique, later coined the Yarzagaray technique by Raimondi [54], remained relatively the same over the years with very slight alterations reported in literature, in terms of technique and post-operative care (Fig. 1.). After isolating the gallbladder, West et al. put 2 concentric purse-string 3-0 nonabsorbable sutures, and a small incision was made in it. Bile was extracted in a minor quantity on this occasion. The distal end of the shunt, equipped with a low-pressure one-way valve, was coiled in a non-obstructive pattern over the dome of the right hepatic lobe and then inserted in the gallbladder where the purse strings were used to secure the catheter at the level of the metal connector [70]. After ensuring that the distal catheter is properly positioned in the cavity of the gallbladder, Girotti et al. used the ends of the purse-string sutures to attach them to the anterior peritoneum [21]. Lyngdoh et al. brought an alteration to the Yarzagaray method by inserting up to $7 \mathrm{~cm}$ of the distal catheter in the cavity of the gallbladder. He did so by attaching the tube around the connecter to the gallbladder serosa and using 2 purse strings [38]. Aldana et al. sectioned the distal catheter $2.5-3 \mathrm{~cm}$ from the end and attached it to a Holter type A nonferromagnetic straight metal connector which eventually was introduced in the gallbladder [2]. Ketoff et al. used a multiperforated tapered silastic catheter (Dow Corning, Midland, MI) inserted in the gallbladder [34], and Olavarria et al. and Shakir et al. specify the barium impregnated nature of the distal tubing $[47,60]$.

The length of the segment of the distal catheter which is inserted in the gallbladder also seems to vary. In most cases, around $4-5 \mathrm{~cm}$ of the tube was placed in the cavity; however, West et al. report inserting $2 \mathrm{~cm} \mathrm{[70],} \mathrm{Girotti} \mathrm{et} \mathrm{al.} 6 \mathrm{~cm}$ [21], and Lyngdoh et al. $7 \mathrm{~cm} \mathrm{[38].} \mathrm{Despite} \mathrm{these} \mathrm{variations,} \mathrm{there}$ has been no particular documented correlation between this aspect and shunt prognosis.

In addition, Aldana et al. also described their type of antimicrobial prophylaxis by using one preoperative intravenous dose of cefazolin $(25 \mathrm{mg} / \mathrm{kg})$ and an intraoperative bacitracin solution $(50,000 \mathrm{U}$ in $500 \mathrm{ml}$ of saline) for cavity irrigation [2]. In the case of Rajaraman et al., to test for any signs of leakage of the VCS, a radionuclide cholescintigraphy scan was performed post-operatively [55], whereas Lyngdoh et al. used an MRI cholangiogram to identify any potential postsurgical issues [38].

More recent descriptions of the technique have been done by Matushita [41] and by Fulkerson et al. in Cohen-Gadol's Neurosurgical Atlas, in which the technique follows most of the steps of the original procedure [19]. However, over the many decades since the first intervention was performed, various valve systems and components of shunt systems have been introduced in clinical routine, making it difficult to draw specific conclusions on VCS efficiency.

Unidirectional valves have been used in all cases of VCSs with the intention of preventing bile reflux. Despite this property, a few cases have been reported where bile managed to ascend, causing bilious ventriculitis in one case and death due to saponification and emulsification in another case. The valve was tested before the intervention and after the complication and the reflux system seemed to be patent. It has been hypothesized that increased abdominal pressure caused by coughing after the surgery could have generated a disruption in the valve mechanism and this could have led it to fail. Furthermore, the majority of authors advocate for a low-pressure valve as the increased intracholecystic pressure during contraction contributes to the valve pressure. West et al. reports using very lowpressure one-way valves in most cases justifying that the intrinsic biliary resistance maintained appropriate intracranial pressure [70]. Ketoff et al. and Girotti et al. on the other hand use a medium pressure valve with good results [21, 34]. Olavarria et al. specify using a Delta 1 valve [47], Aldana mention both Delta and Holter valves in their protocol [2], whereas Lyngdoh et al. used a Chabbra shunt which is designed with two slit valves [38].

To minimize the chance of complications, a one-way, lowpressure valve is thus proposed by most cases in literature and these seem to be fit for purpose, but further research could reveal the potential of other types of valves.

Apart from the classical open subcostal approach to insert the distal end of the shunt, several other techniques have been documented. Percutaneous insertion of a VCS was also reported in a 9-month-old with hydrocephalus due to a grade 4 intraventricular hemorrhage [60]. Furthermore, Pancucci et al. were the first to describe the successful positioning of a VCS with the assistance of laparoscopic surgery in a 4month-old patient with hydrocephalus secondary to an optic chiasmal hypothalamic glioma [49]. Ignacio et al. also used this approach in a 20-month-old patient with increased CSF levels due to a grade 3 ventricular hemorrhage [28]. In the case presented by Pancucci et al., the technique was done with the help of a pediatric surgeon through a three-port laparoscopic approach, and a 7-French pigtail catheter was inserted in the fundus of the gallbladder via the Seldinger technique. Their surgical intervention was based on a study by Soleman et al. on laparoscopic insertion of ventriculoperitoneal shunts [64]. 
Table 2 Adult hydrocephalus

\begin{tabular}{|c|c|c|c|c|c|c|}
\hline Year & Author & Number of patients & Age & Previous shunt & Follow-up & Complications \\
\hline 1997 & Ketoff et al. & $\begin{array}{l}16 \text { (not specified how } \\
\text { many were adults) }\end{array}$ & $0.9-23 y$ & $\begin{array}{l}\text { VP, VA, VPL, VSaph } \\
1 \text {-none }\end{array}$ & $4 w-7.5 y$ & $\begin{array}{l}\text { 9- no complications } \\
\text { 7- complications (shunt } \\
\text { obstruction/disconnection/infection, } \\
\text { enterotomy, pseudomembranous colitis, } \\
\text { subdural hematoma, slit ventricles, } \\
\text { cellulitis, wound dehiscence, unilateral } \\
\text { hydrocephalus from an undrained ventricle } \\
\text { contralateral to ventriculostomy) }\end{array}$ \\
\hline 2007 & Fountas et al. & 1 & $31 \mathrm{y}$ & Not specified & $20 y$ & Cholelithiasis \\
\hline 2009 & Girotti et al. & 1 & $46 \mathrm{y}$ & VP, VPL & $1 \mathrm{y}$ & No complications \\
\hline 2010 & Polo et al. [52] & 1 & $33 \mathrm{y}$ & $\mathrm{VP}$ & $10 \mathrm{mo}-3 \mathrm{y} ?$ & No complications \\
\hline 2016 & $\begin{array}{l}\text { Hasslacher-Arellano } \\
\text { et al. [25] }\end{array}$ & 1 & $27 \mathrm{y}$ & VP & Not specified & Not specified \\
\hline 2017 & Guclu et al. & 1 & $44 y$ & VP, VA & Not specified & Not specified \\
\hline 2017 & Scaife et al. & 1 & $20 y$ & VP, VPL, VA & Not specified & $\begin{array}{l}\text { Ascending cholangitis due to a retained } \\
\text { fragment in the gallbladder which later } \\
\text { migrated to CBD and got lodged in the } \\
\text { ampulla }\end{array}$ \\
\hline
\end{tabular}

The technique appears to have been better tolerated than the subcostal approach, and the patient was complication-free at 14 months of follow-up.

A particularity of the distal catheter in children is allowing a sufficient length of tubing in the abdomen to adapt to the growth of the patient. The issue of the length of the VCS distal catheter has not been thoroughly discussed in literature. Stringel et al. and Olavarria et al. placed around 30-40 cm of redundant catheter in the abdomen to facilitate this aspect $[47,66]$, whereas Novelli et al. inserted around 15-20 cm [46]. Some authors mention adding excess redundant catheter $[2,48,70]$, but do not specify the exact length. Extended tubing is generally well tolerated in children with VP shunts [12] and this progressively uncoils as the child grows. This would occur in a similar way in a pediatric patient with a VCS inserted either classically or laparoscopically. A few potential consequences can occur if the distal catheter does not have an adequate length. As the patient grows, there would be increasing tension applied to the site where the shunt is inserted in the gallbladder. This can lead to the dislodgement of the shunt from the cholecystic compartment. Subsequently, not only would the CSF be diverted into the peritoneal cavity but bile would also leak into the abdomen. This can cause serious complications such as bile peritonitis as described by Kulwin et al. [35]. Some authors have also reported a pediatric case where the straight connector was retained in the gallbladder after the shunt was disconnected [55]. Fortunately, their patient did not show any form of leakage, but in these cases, it would be important to inspect the cholecystic compartment as well and close it if necessary, in order to avoid the risk of bile leak in the abdomen.

\section{VCS in Adult Hydrocephalus}

There have been 6 documented adult patients, between the ages of 20 to 46 years, that have undergone VCS for hydrocephalus of different etiologies (Table 1). The number of adult patients is potentially higher, but there is no indication as to how many patients over the age of 18 years old are in Ketoff's patient population [34]. All cases had a previous form of the shunt that either failed multiple times or required converting to a different type of shunt. Girotti et al. illustrate the case of a 46-year-old with hydrocephalus due to several cerebral masses who underwent ventriculoperitoneal shunt insertion and required up to 4 revisions. After the failure of the ventriculoperitoneal shunt, a VPL shunt was inserted but failed as well due to inappropriate absorption. The final decision was to resort to a VCS, which was found to be very effective at 1-year follow-up [21]. Guclu et al. go even further and perceive VCS as a salvage procedure in their case report, where other VP shunt and VA shunts have been unsuccessful [22]. Despite this aspect, not all VCSs prove to be so effective.

The period in which VCSs are patent also varies. Fountas et al. describe a case of a 51-year-old who was admitted to the emergency room 20 years after having a VCS inserted. The patient was investigated, and it appears that a calculus formed around the distal end of the shunt and had to be removed along with the entire gallbladder in a cholecystectomy intervention. Subsequently, the shunt was converted to a VPL shunt. Despite the unfortunate outcome, this case describes the longest period of time in which a VCS was patent [17].

It appears that very few adult cases can be found in literature, and databases can be inconsistent, lacking certain details, 
such as follow-up times and complication rates. Therefore, statistical analysis is difficult to construct.

\section{VCS in Pediatric Hydrocephalus}

The majority of cases discussed in literature about VCS involve pediatric patients. A total of 105 patients have been identified in 29 articles comprising 4 larger case series (Table 2). On top of that, the case series of 15 patients attributed to Luis Yarzagaray could potentially be included, adding up to a total of 120 patients. Given that the work of Yarzagaray, L. has never been published and only mentioned in Raimondi's Pediatric Neurosurgery Textbook, it is difficult to incorporate them without any proper details. Furthermore, some authors fail to report the age of the patients, thus it is difficult to include them in any of the adult or pediatric populations [36, 54].

Other CSF derivations have been sought before performing a VCS. Most authors report multiple attempts on VP or VA shunts. On a few occasions, more infrequent shunts have been mentioned as previous options, such as ventriculosaphenous [34], ventriculofemoral [56], or ventriculojugular shunt [2]. West described patients that had up to 6 revisions of their VP/VA shunts [70]. However, 5 studies presented cases that had a VCS as a first line of treatment. Pal et al. report the case of a 6-month-old patient with postmeningitis hydrocephalus shunted with VCS [48]. The initial plan was to perform a VP shunt, but after uncovering the extent of the intra-abdominal adhesions, the therapeutic decision was shifted to a VCS. Ketoff et al. and Aldana et al. each have a patient for which VCS was the first intent, one of the reasons being previous abdominal surgery $[2,34]$.

The largest case series up to this date remains West et al. with 25 patients over a period of 16 years. The patients' ages varied between 6 months and 16 years and included congenital hydrocephalus or hydrocephalus secondary to myelomeningocele, meningitis, cerebral masses, and intraventricular hemorrhage. All except one had previous failed VP and VA shunts. In this series, three patients deceased in the following 4 to 24 months due to unrelated causes. Despite some manageable complications, the authors report good outcomes in the majority of the remaining patients; 14 having the VCS in place long-term, among which 6 even for up to 9 years [70]. The second largest case series is a more recent study belonging to Aldana et al. with a total of 18 patients, $61 \%$ of which did not have any immediate shunt complications. In a long-term follow-up lasting between 1 and 8.5 years, $72 \%$ of cases had functional shunts (13 out of 18) [2]. Ketoff et al. also had good results with a larger case series of 16 patients, out of which 11 were still working at a median follow-up rate of 3 years, thus a complication rate of $43.7 \%$ [34]. Stringel et al. reported a slightly lower complication rate of $37.5 \%$ [66].
There have been a number of case reports and case series $(8$ out of 29) that have presented no complications. Novelli et al. did not identify any issues with the VCS in any of their 6 patients. They had a mean follow-up period of 32 months, some shunts being patent up to 8 years [46].

The large numbers of VCS reported in literature are case reports with various particularities, from etiology and technique to complications and outcomes. In the case of optic chiasmal hypothalamic astrocytoma (OCHA), there have been some reports in which VCS was a suitable option. It is a documented fact that ascites is a significant complication in OCHA patients [61], thus making the VP shunt an unfeasible option [20]. In an attempt to find an alternative, Olavarria et al. described 4 cases of OCHA treated with VCS. There were no mortalities, and all VCSs were patent for a significant amount of time. Three out of four, however, had to be converted to different types of shunts. One remained in place and had a longstanding functional VCS at 4 years of follow-up [47]. In addition, Pancucci et al. performed a laparoscopic VCS as the first line of treatment in a patient with OCHA and his results were promising, as no complication was demonstrated at 14 months of follow-up [49]. Alraee et al. also described a laparoscopic approach to place a VCS in a patient with an extensive optic glioma, which eventually developed gallbladder stones [4].

Lyngdoh et al. has treated post-tuberculous hydrocephalus with tubercular adhesive peritonitis with a VCS in 2 separate cases. Due to the difficulty of managing this pathology [62], the authors advocate for considering a VCS for treatment [38].

Another pathology in which VCS has been proposed as a solution is hydrocephalus in the context of congenital plasminogen deficiency. Weinzierl et al. reported the case of 2 pediatric patients with this hematological disorder that were initially treated unsuccessfully with a VP shunt. Given the thrombogenic nature of this disorder, VA shunts can have unfavorable consequences. The first patient was treated both with VP shunt and VA shunt and resulted in failure. Subsequently, VCS was implanted, and functioned well for 2 years, until it got occluded and eventually led to the patient's death. The second patient was operated sooner with a VCS and has had a significantly better outcome at 3 years of followup. The authors suggest that early management can make a difference in this type of pathology [69]. Furthermore, Demetriades et al. describe their experience with VCS in a 9-month-old female patient with congenital plasminogen deficiency. After having a failed VP shunt, the authors did not consider VA shunt and opted for a VCS. This proved to be a practical decision and the patient had a good post-operative outcome with a functional shunt at 46 months of follow-up. Far from suggesting this procedure should constitute a standard in these clinical entities, different authors suggest taking into consideration this site as a viable alternative [14]. 


\section{Contraindications}

Any biliary pathology could potentially impact the outcome of a VCS. Thus, a thorough preoperative assessment is required. It is first important to establish the presence of a gallbladder, either by identifying it via ultrasonography or by enquiring of any cholecystectomy in the past medical history.

Once visualized, imagistic investigation would help in recognizing any issues. An intrahepatic or hypoplastic gallbladder would be a contraindication as it would not be able to accommodate larger volumes of fluid.

Biliary infections such as cholecystitis, gallbladder abscesses, or predisposing factors to cholelithiasis, such as hemolytic anemias (sickle cell disease, hereditary spherocytosis) would impair VCS function.

According to Alraee et al., the presence of sludge in the gallbladder, without any signs of inflammation or biliary duct dilation, does not represent a contraindication. They managed a pediatric case of hydrocephalus secondary to optic glioma, in which a VCS was inserted in a child with known biliary sludge. The sludge was removed prior to shunt placement by irrigating the gallbladder with normal saline. Eventually, the patient developed jaundice and was diagnosed with cholecystitis and cholangitis. The case was managed by performing an ERCP with sphincterotomy and stone extraction without cholecystectomy or shunt removal, and the child was complication-free at 12 months of follow-up [4]. This is in contrast with James et al. who resorted to shunt removal [32].

Ignacio et al. delineate a list of contraindications in their decision algorithm for VCS placement. As their study is focused on laparoscopic placement, the inability of tolerating a pneumoperitoneum is also mentioned. General contraindications such as severe abdominal adhesions would also be a criterion, such as in the case of a VP shunt [28].

\section{Specific VCS complications}

In terms of complications, various authors have documented aspects that are common to all shunts, such as shunt blockage or infection, but also details that were specific to VCS. Bernstein et al. outline a fatality case of biliary ventriculitis secondary to a gallbladder shunt. The report written in 1985 appears to be the only case that succumbed as a direct result of the shunt system [9]. Kulwin et al. report the case of a patient with a gallbladder shunt that developed bile peritonitis due to a fracture of the catheter below the valve and required to be removed and converted to a VA shunt [35]. MRSA ventriculitis has been cited in a 13-month-old patient who presented septic to the hospital. She was initially started on intravenous vancomycin but did not show signs of improvement, so intraventricular administration was commenced. Improvement was noted, but the shunt had to be converted to a ventriculoureteral one [68]. To support this approach, most experts recommend combined intraventricular (IVT) and IV antibiotic therapy. They also recommend removing the shunt and placing an EVD, rather than performing externalization of the infected shunt $[11,30,31]$.

Although not reported, Demetriades et al. also remark that cholecystitis can potentially yield ascending and descending VCS infections [56] as it has been observed in VP shunts [40].

Specific mechanical complications include obstruction due to retained distal metal connector after a VCS was removed as shown by Parikh et al. The 26-year-old patient suffered 2 acute cholangitis attacks and renal failure as a result of sepsis so she eventually had to undergo cholecystectomy and the removal of the obstruction from the common bile duct [50]. Another case of cholangitis due to a retained catheter fragment was reported by Scaife et al. in a patient that developed symptoms several years after VCS removal [57]. Obstruction can also be caused by a calculus formation around the distal end of an existing shunt. Fountas describes cholelithiasis in a longstanding shunt that eventually led to it being removed through a cholecystectomy [17], whereas Alraee et al. performed the stone extraction through an endoscopic retrograde cholangiopancreatography (ERCP) with sphincterotomy, without shunt removal [4]. Surfield and Klein also identify the same issue in an adult patient [67].

Rajaraman et al. draw attention to a general state of awareness when dealing with a VCS. As it is not so commonly used, radiologists can confuse the VCS to a complication of a VP shunt in the absence of an accurate clinical history [55].

Gallbladder atony has also been documented by West et al. in 3 children 3-13 months following shunt placement, but the issue resolved after intravenous administration of cholecystokinin. Narcotic medication and Oddian spasm were suspected to be the underlying mechanism of this disturbance [70].

Intra-abdominal complications such as gastric [3] or intestinal perforation [73] have been frequently reported in VP shunts. In cases of biliary CSF diversion, Ketoff et al. reported a patient who had an enterotomy and pseudomembranous colitis post-VCS insertion [34], and West et al. had one patient in their case series who experienced a small bowel fistula due to a VCS [70]. In addition, since the bile is diluted with CSF, there is a possibility this could impact its capacity to emulsify lipids. Although not an aspect that has been properly investigated, it is worth taking this possibility into account and making adequate adjustments to the patient diet if necessary.

Another complication that has been evaluated by Frim et al. is the frequent post-prandial headaches that can occur in some patients. This aspect was quantified in a noninvasive telemetric study and found that the reason for this is increased intraventricular pressure after having a meal. The study was performed on only one patient, so it is difficult to assess whether it is caused by all types of feeding or only by fatty meals [18]. 


\section{Future perspectives}

There does not seem to be a trend in terms of what type of hydrocephalus can be shunted with a VCS. These types of shunts have been evaluated in various instances when other shunts failed and have rendered good results. Various studies have compared VP and VA shunts and have concluded that there is variably no difference between the complication rate of the two [27], but no comparison has been made between case series of VP or VA shunts and VCS. VP shunts have been subjected to statistically relevant comparisons to other types of shunts such as the VPL shunt [51] or VA shunt [37] and concluded that there are equally as effective as the first option. When trying to choose a second option after a VP shunt has failed, careful consideration should be made to the complications that can occur in patients. In this matter, there is a significant difference in what complications can occur from VA [24] shunts when compared to VCSs. Arguably, VCSs are significantly less at risk of causing a life-threatening issue, compared to the risks that can occur from the migration, thrombosis, malposition, or infection of a shunt in the atrium. Despite this aspect, it is important to note that relevant comparisons are difficult to make, as the number of patients who underwent VC shunting is considerably smaller.

There is no established timeline of follow-up for VCS patients, some of the cases being reviewed early due to potential complications. Given that this technique is not widely performed and complications have been reported even after 1 week, it would be advisable to have early follow-up with adequate imaging and blood tests.

For follow-up purposes, shunt X-ray series are a very useful investigation for VP shunts [15] and these could prove relevant for VCSs as well, particularly the abdominal X-ray to assess the distal component. Ultrasonography is an invaluable resource for biliary evaluation [16] and this could be performed both immediately post-op to ensure proper gallbladder emptying as Aldana et al. suggest as well as routinely in an outpatient setting [2]. In situations where the ultrasound assessment is not satisfactory, CT imaging can be used for further evaluation. Some authors such as Lyngdoh used MR cholangiography at follow-up [38]. Blood tests should also be performed and aim at evaluating for any sign of infection and or abnormality in liver function tests.

VCSs have shown promising results in patients with congenital plasminogen deficiency, post-tuberculous hydrocephalus, and OCHA patients, but further research must be conducted on larger populations before they are acknowledged as a viable alternative. It would be difficult to recommend VCS as first-line treatment in these cases, but it should definitely be taken into account given that there are studies in literature that suggest its effectiveness.

There is a significant interstudy variability among current literature regarding VCS outcomes. Girotti et al. conducted a review in 2009 on the largest VCS case series at that point, and found a percentage of $63 \%$ of patients that benefited from a long-term good outcome. These results would be comparable to VP or VA shunts, but further analysis is required to clarify different aspects regarding indication. It is also difficult to statistically evaluate as there is quite an inconsistency in data in terms of the number of previous shunting procedures or follow-up time. Also, there are a significantly lower number of cases compared to other diversion options [21].

\section{Conclusion}

In neurosurgical literature, ventriculocholecystic shunts seem to have shown encouraging results in both adults and children. There are several case series that exhibit results comparable to ventriculoperitoneal or ventriculoatrial shunts and there are indications that they could be a feasible option in congenital plasminogen deficiency, optic chiasmal hypothalamic astrocytomas, and posttuberculous hydrocephalus. Some authors advocate for VCS as an early alternative; however, there are many questions regarding this CSF diversion that are open and difficult to answer, mainly because of the small number of patients treated with this method up until now. VCS cannot be viewed as a first-line strategy as there are still aspects regarding indications, contraindications, and follow-up that require clarification. It is quintessential that a surgeon is faced with all the current facts before deciding to undertake such a procedure that can prove as challenging as other shunting methods. Further research with larger patient populations and with rigorous statistical parameters are necessary to establish the current role of the ventriculocholecystic shunt.

Acknowledgments The authors would like to express their gratitude to the Library of the University Hospitals Bristol, for providing the articles for this review on such short notice, and also to Dr. Elena A. Munge for her contribution to finding some of the articles. Furthermore, they would like to thank Dr. Selda Boztepe for providing translation from Turkish literature and Miss Sandra Sanchidrián Garcia for providing translation from Spanish literature. In addition, the authors would also like to thank Miss Sandra Al-Assaf for providing the illustration for this article.

Authors' contributions Concept and design: Morosanu CO; draft writing: Morosanu CO and Priscu A; data collection: Morosanu CO and Priscu A; literature analysis: Morosanu $\mathrm{CO}$ and Priscu A; study supervision: Florian IS; critical revision of the first draft: Florian IS; revision of submitted manuscript: all authors; approval of submitted version: all authors.

Data availability Not applicable.

\section{Compliance with ethical standards}

Conflict of interest The authors declare that they have no conflict of interest. 
Ethics approval No ethical approval was required for the manuscript (review).

Consent to participate No consent to participate was required for the manuscript (review).

Consent for publication No consent for publication was required (review).

\section{Code availability Not applicable.}

Open Access This article is licensed under a Creative Commons Attribution 4.0 International License, which permits use, sharing, adaptation, distribution and reproduction in any medium or format, as long as you give appropriate credit to the original author(s) and the source, provide a link to the Creative Commons licence, and indicate if changes were made. The images or other third party material in this article are included in the article's Creative Commons licence, unless indicated otherwise in a credit line to the material. If material is not included in the article's Creative Commons licence and your intended use is not permitted by statutory regulation or exceeds the permitted use, you will need to obtain permission directly from the copyright holder. To view a copy of this licence, visit http://creativecommons.org/licenses/by/4.0/.

\section{References}

1. Ackerman NB, Sillin LF, Suresh K (1985 Feb 1) Consequences of intraperitoneal bile: bile ascites versus bile peritonitis. Am J Surg 149(2):244-246

2. Aldana PR, James HE, Postlethwait RA (2008 Apr 1) Ventriculogallbladder shunts in pediatric patients. J Neurosurg Pediatr 1(4):284-287

3. Alonso-Vanegas M, Alvarez L, Delgado L, Mendizabal R, Jiménez L, Sanchez-Cabrera JM (1994) Gastric perforation due to ventriculo-peritoneal shunt. Pediatr Neurosurg 21(3):192-194

4. Alraee S, Alshowmer S, Alnamshan M, Azzubi M (2020) Management of ventriculo-gallbladder shunt in the presence of gallstones. BMJ Case Rep 13:e234775

5. Ames CD, Jane JA Jr, Jane JA Sr, Campbell FG, Howards SS (2001 Apr) A novel technique for ventriculovesical shunting of congenital hydrocephalus. J Urol 165(4):1169-1171

6. Andersson R, Sonesson A, Larsson L, Schalén C, Tranberg KG (1991 Feb) Bile increases lipopolysaccharide release in experimental E. coli peritonitis. Eur J Surg 157(2):117

7. Andrews RJ, Bringas JR, Alonzo G (1994) Cerebrospinal fluid pH and $\mathrm{PCO} 2$ rapidly follow arterial blood $\mathrm{pH}$ and $\mathrm{PCO} 2$ with changes in ventilation. Neurosurgery. 34(3):466-470 discussion 470

8. Barami K, Sood S, Ham S, Canady A (1998) Chemical meningitis from bile reflux in a lumbar-gallbladder shunt. Pediatr Neurosurg 29(6):328-330

9. Bernstein RA, Hsueh W (1985 Jan 1) Ventriculocholecystic shunt. A mortality report. Surg Neurol 23(1):31-37

10. Boyer JL (2013 Jul) Bile formation and secretion. Compr Physiol 3(3):1035-1078

11. Brown EM, Edwards RJ, Pople IK (2006 Apr 1) Conservative management of patients with cerebrospinal fluid shunt infections. Neurosurgery. 58(4):657-665

12. Couldwell WT, Lemay DR, McComb JG (1996) Experience with use of extended length peritoneal shunt catheters. J Neurosurg 85(3):425-427

13. Csendes A, Fernandez M, Uribe P (1975 Jun 1) Bacteriology of the gallbladder bile in normal subjects. Am J Surg 129(6):629-631
14. Demetriades AK, Haq IZ, Jarosz J, McCormick D, Bassi S (2013 Aug 1) The ventriculocholecystic shunt: two case reports and a review of the literature. Br J Neurosurg 27(4):505-508

15. Desai KR, Babb JS, Amodio JB (2007 May 1) The utility of the plain radiograph "shunt series" in the evaluation of suspected ventriculoperitoneal shunt failure in pediatric patients. Pediatr Radiol 37(5):452-456

16. Finberg HJ, Birnholz JC (1979 Dec) Ultrasound evaluation of the gallbladder wall. Radiology. 133(3):693-698

17. Fountas KN, Kassam MA, Grigorian AA (2007) A rare, delayed complication of a ventriculogallbladder shunt: case report and review of the literature. Neurosurg Focus 22(4):1-3

18. Frim DM, Lathrop D, Chwals WJ (2001) Intraventricular pressure dynamics in ventriculocholecystic shunting: a telemetric study. Pediatr Neurosurg 34(2):73-76

19. Fulkerson D, Cohen-Gadol A et al (2020) Neurosurg Atlas. https:// doi.org/10.18791/nsatlas.v12.5

20. Gil Z, Beni-Adani L, Siomin V, Nagar H, Dvir R, Constantini S (2001 Jun 1) Ascites following ventriculoperitoneal shunting in children with chiasmatic-hypothalamic glioma. Childs Nerv Syst 17(7):395-398

21. Girotti ME, Singh RR, Rodgers BM (2009 Aug 1) The ventriculogallbladder shunt in the treatment of refractory hydrocephalus: a review of the current literature. Am Surg 75(8):734-737

22. Guclu B, Hicdonmez T, Adilay U, Altuntas YE (2017) Successful application of the Ventriculo-Gallbladder shunt: a salvage procedure. Turk Neurosurg 30(1):138-140

23. Hamamcioglu MK et al (2005) Ventriculo-gallbladder shunting as an alternative treatment for complicated shunt dysfunction: Case report. Turk Norosir Derg 15:169-172

24. Hanak BW, Bonow RH, Harris CA, Browd SR (2017) Cerebrospinal fluid shunting complications in children. Pediatr Neurosurg 52(6):381-400

25. Hasslacher-Arellano JF et al (2016) Ventriculo-gallbladder shunt: an alternative for the treatment of hydrocephalus. Cirugía y Cirujanos (English Edition) 84(3):225-229

26. Henderson D, Budu A, Horridge M, Jesurasa A, Sinha S, Ushewokunze S, Fisher R (2019 Sep) The ventriculo-cholecystic shunt: does CSF volume matter? Childs Nerv Syst 35(9):15571560

27. Hung AL, Vivas-Buitrago T, Adam A, Lu J, Robison J, Elder BD, Goodwin CR, Jusué-Torres I, Rigamonti D (2017 Jun 1) Ventriculoatrial versus ventriculoperitoneal shunt complications in idiopathic normal pressure hydrocephalus. Clin Neurol Neurosurg 157:1-6

28. Ignacio RC Jr, Schermerhorn SM, Marrotte AJ, Prieto JM (2019 Aug 1) Laparoscopic ventricular-cholecystic shunt. J Pediatr Surg Case Rep 47:101233

29. Ikeda T, Yanaga K, Kusne S, Fung J, Higashi H, Starzl TE. Sterility of bile in multiple-organ donors. Transplantation. 1990 Mar;49(3): 653. https://doi.org/10.1097/00007890-199003000-00036

30. James HE, Bradley JS (2008) Aggressive management of shunt infection: combined intravenous and intraventricular antibiotic therapy for twelve or less days. Pediatr Neurosurg 44(2):104-111

31. James HE, Bradley JS (2008) Management of complicated shunt infections: a clinical report. J Neurosurg Pediatr 1:223-228

32. James H, Aldana P, Postlethwait R (2008 Apr 1) Technical aspects of ventriculogallbladder shunts: the surgical team preoperative assessment. Operative Intervention and Postoperative Assessment: A Clinical Report. J Neurosurg Pediatr 1(4):A356-A357

33. Jones RF, Currie BG, Kwok BC (1988 Dec) Ventriculopleural shunts for hydrocephalus: a useful alternative. Neurosurgery. 23(6):753-755

34. Ketoff JA, Klein RL, Maukkassa KF (1997 Feb 1) Ventricular cholecystic shunts in children. J Pediatr Surg 32(2):181-183 
35. Kulwin CG, Margaron FC, Leys CM, Boaz JC, Fulkerson DH (2014) Ventriculogallbladder shunt fracture: bile peritonitis: case illustration. J Neurosurg Pediatr 13(1):94

36. Leyva Mastrapa T, Fernández LA, Martínez MA, Martinez Millares AR (2004) Derivación ventrículo-vesicular-biliar. Una opción de trata-miento en la hidrocefalia. Rev Argent Neurocir 18(supl2):27-30

37. Liu A, Sankey EW, Jusué-Torres I, Patel MA, Elder BD, Goodwin CR, Hoffberger J, Lu J (2016 Apr) Rigamonti D Clinical outcomes after ventriculoatrial shunting for idiopathic normal pressure hydrocephalus. Clin Neurol Neurosurg 143:34-38

38. Lyngdoh BT, Islam MS (2012 Dec 1) Ventriculocholecysto shunt: a solution to recurrent shunt complications in comorbid posttubercular hydrocephalus with tubercular adhesive peritonitis. Acta Neurochir 154(12):2267-2270

39. Marteau C, Sastre B, Iconomidis N, Portugal H, Pauli AM, Gérolami A (1990 Jun) pH regulation in human gallbladder bile: study in patients with and without gallstones. Hepatology. 11(6): 997-1002

40. Martínez-Lage JF, Girón Vallejo O, López López-Guerrero A, Martínez-Lage Azorín L, Roqués JL, Almagro MJ (2008) Acute cholecystitis complicating ventriculo-peritoneal shunting: report of a case and review of the literature. Childs Nerv Syst 24:777-779

41. Matushita H. (2020) How to Perform a Ventriculo-gallbladder CSF Shunt. In: Di Rocco C, Pang D, Rutka J (eds) Textbook of Pediatric Neurosurgery. Springer, Cham

42. Miele VJ, Bendok B, Bloomfield SM, Ondra SL, Bailes JE (2004 Aug 1) Ventriculoperitoneal shunt dysfunction in adults secondary to conditions causing a transient increase in intra-abdominal pressure: report of three cases. Neurosurgery. 55(2):444-E448

43. Morosanu CO, Filip GA, Nicolae L, Florian IS (2020) From the heart to the bladder-particularities of ventricular shunt topography and the current status of cerebrospinal fluid diversion sites. Neurosurg Rev 2020 Jun;43(3):847-860. https://doi.org/10. 1007/s10143-018-1033-2

44. Negrete HO, Lavelle JP, Berg J, Lewis SA, Zeidel ML (1996 Oct) Permeability properties of the intact mammalian bladder epithelium. Am J Phys 271(4 Pt 2):F886-F894

45. Neiderhiser DH, Harmon CK, Roth HP (1976 Mar) Absorption of cholesterol by the gallbladder. J Lipid Res 17(2):117-124

46. Novelli PM, Reigel DH (1997) A closer look at the ventriculogallbladder shunt for the treatment of hydrocephalus. Pediatr Neurosurg 26(4):197-199

47. Olavarria G, Reitman AJ, Goldman S, Tomita T (2005 May 1) Postshunt ascites in infants with optic chiasmal hypothalamic astrocytoma: role of ventricular gallbladder shunt. Childs Nerv Syst 21(5): 382-384

48. Pal K, Jindal V (2007 Jun 1) Ventriculo-cholecystic Shunt in the Management of Hydrocephalus. Indian Pediatr 44(6):435-437

49. Pancucci G, Plaza-Ramirez E, Driller C, Miranda-Lloret P, BotellaAsunción C (2019 Aug 1) Laparoscopy-assisted placement of a ventriculobiliary shunt: a technical note. Childs Nerv Syst 35(8): 1397-1400

50. Parikh P, Carratola MC, Malik T (2013) Removal of a retained fragment of a ventriculo-gallbladder shunt in the common bile duct. Eur J Surg Sci 4(3):126

51. Piatt JH Jr (1994) How effective are ventriculopleural shunts? Pediatr Neurosurg 21(1):66-70

52. Polo VJ, Usuaga AH, España PJ, Cortes SE, Díaz CF, Orozco LJ et al (2010) Derivación ventrículo-vesicular: una alternativa para eltratamiento de la hidrocefalia. Reporte de casos y revisión dela literatura. Neurocien Colom 17:76-83.21

53. Rahmani V, Molazem M, Jamshidi S, Vali Y, Hanifeh M (2015 Sep) Evaluation of gallbladder volume and contraction index with three-dimensional ultrasonography in healthy dogs. J Vet Med Sci 77(9):1157-1161

54. Raimondi A.J. (1998) Hydrocephalus. In: Pediatric Neurosurgery. Springer, Berlin, Heidelberg

55. Rajaraman V, Schlenk R (2000) Schulder M Beware of the ventriculogallbladder shunt. Pediatr Radiol 30(4):274-275

56. Rivero-Garvía M, Pancucci G, Morcillo J, Millán A, MárquezRivas J (2015) Ventriculobiliary shunts, another option. Pediatr Neurosurg 50(3):152-156

57. Scaife M, Abegglen R, Vila C, Stahlfeld K (2018 Jun 1) Abnormal presentation of ascending cholangitis. Clin Case Rep 6(6):11721173

58. Scheeres DE, Magnuson TH, Pitt HA, Bastidas JA, May CA, Lillemoe KD (1990 Jun) The effect of calcium on gallbladder absorption. J Surg Res 48(6):547-551

59. Sepúlveda Martínez V, Saitua Doren F, Marengo Olivares J. Derivación ventrículo vesicular como tratamiento de disfunción valvular recurrente. Rev Ped Elec [en línea]. 2012;9(2). ISSN 0718-0918 144

60. Shakir BA, Heger IM (2013 Aug 15) Percutaneous ventriculocholecystic shunt as a cerebrospinal fluid diversion alternative: technical report. Contemp Neurosurg 35(16):1-5

61. Shuper A, Horev G, Michovitz S, Korenreich L, Zaizov R, Cohen IJ (1997 Jul) Optic chiasm glioma, electrolyte abnormalities, nonobstructive hydrocephalus and ascites. Med Pediatr Oncol 29(1):33-35

62. Sil K, Chatterjee S (2008 Sep 1) Shunting in tuberculous meningitis: a neurosurgeon's nightmare. Childs Nerv Syst 24(9):10291032

63. Smith GW, Moretz WH, Pritchard WL (1958) Ventriculo-biliary shunt: a new treatment for hydrocephalus. Surg Forum 9:701-705

64. Soleman J, Schneider CA, Pfeifle VA, Zimmermann P, Guzman R (2017 Mar 1) Laparoscopic-assisted ventriculoperitoneal shunt placement in children younger than the age of 1 year. World Neurosurg 99:656-661

65. Starinsky R, Alon Z (1994 Jun) Gallbladder size: is it affected by the oral intake of water or dilute contrast medium? J Ultrasound Med 13(6):435-438

66. Stringel G, Turner M, Crase T (1993 Sep 1) Ventriculo-gallbladder shunts in children. Childs Nerv Syst 9(6):331-333

67. Surfield GA, Klein RL (2006 Nov 1) Case report of symptomatic cholelithiasis after ventricular cholecystic shunt. J Pediatr Surg 41(11):1933-1934

68. Weiner GM, Bui CJ, Steele RW (2011) An infant with an MRSA ventriculo-gallbladder shunt infection. Clin Pediatr 50(3):269-271

69. Weinzierl MR, Collmann H, Korinth MC, Gilsbach JM, Rohde V (2007) Management of hydrocephalus in children with plasminogen deficiency. Eur J Pediatr Surg 17(02):124-128

70. West KW, Turner MK, Vane DW, Boaz J, Kalsbeck J, Grosfeld JL (1987 Jul 1) Ventricular gallbladder shunts: an alternative procedure in hydrocephalus. J Pediatr Surg 22(7):609-612

71. Woodfield J, Magdum S (2013 Sep-Dec) Failure of peritoneal and gallbladder shunts in a child with craniopharyngioma. J Pediatr Neurosci 8(3):221-223

72. Yoo JH, Kwak HJ, Lee MJ, Suh JS, Rhee CS (2003 Feb) Sonographic measurements of normal gallbladder sizes in children. J Clin Ultrasound 31(2):80-84

73. Zhou F, Chen G, Zhang J (2007 Nov) Bowel perforation secondary to ventriculoperitoneal shunt: case report and clinical analysis. J Int Med Res 35(6):926-929

Publisher's note Springer Nature remains neutral with regard to jurisdictional claims in published maps and institutional affiliations. 